\section{Year in review 2013: paediatric and adult clinical studies}

\author{
Andy Bush, ${ }^{1}$ Ian Pavord ${ }^{2}$
}

This is the first of two reviews of Thorax in 2013 focusing on manuscripts dealing with the clinical aspects of paediatrics and adult respiratory medicine. Our prizes last year were a popular addition and so we have retained this in 2013. Decisions are purely those of the editors and deputy editors. Our only restriction has been to not consider manuscripts from Imperial, Leicester and Oxford, not because they were too numerous or too good (regrettably), but because we have conflicts of interest.

\section{PAEDIATRICS}

Cystic fibrosis (CF) is an area with major research activity, especially with the introduction of new therapies bolstered with good randomised controlled trials. Aerosolised antibiotics have been the mainstay of therapy for chronic Pseudomonas aeruginosa infection since Margaret Hodson's trials in the 1980s, replicated in the USA more than a decade later (if it did not happen in the USA, it did not happen!). Once daily nebulised amikacin had a good profile in a phase II trial $^{1}$ - but should it be reserved for atypical Mycobacterial infection? Dry powder devices are increasingly being used instead of nebulisers to try to reduce treatment burden, so an important study showed that for colomycin the two methods of delivery were equivalent. $^{2}$ An accompanying editorial ${ }^{3}$ discussed how a favourite Thorax set of whipping boys, the National Institute of Health and Care Excellence, have made a dog's breakfast of their recommendations. Finally, non-CF bronchiectasis is an orphan disease, so good to see nebulised ciprofloxacin being shown to be effective in a phase II trial in this group. ${ }^{4}$ Another theme is the increasing realisation of the importance of pulmonary exacerbations (also known as lung attacks) in CF. High frequency chest wall oscillation is an expensive adjunct to airway clearance, which is much hyped at meetings. A randomised controlled trial,

${ }^{1}$ National Heart and Lung Institute, Imperial College, London, UK; ${ }^{2}$ Department of Respiratory Medicine, Nuffield Department of Medicine, University of Oxford, Oxford, UK

Correspondence to Prof Andy Bush, National Heart and Lung Institute, Imperial College, London, SW3 6NP, UK the winner of our bronze award in this category, showed it was inferior to standard cheap positive pressure devices in terms of prevention of exacerbation, the primary endpoint, ${ }^{5}$ and an accompanying editorial pointed out that if spirometry had been used instead, no difference would have been shown. ${ }^{6}$ Byrnes et $a l^{7}$ showed that exacerbations were a marker for progressive lung disease even in preschool children, extending previous observations in older children and adults. ${ }^{8-12}$ Diagnosis of exacerbation is often circular, as we pointed out-it is an exacerbation so I give antibiotics, and I define exacerbation by the fact antibiotics were given-so better objective diagnostic measures are needed. Nick et $a l^{13}$ showed that diagnosis of an exacerbation was improved measuring the upregulation of six genes in peripheral blood leucocytes and validated this in a second cohort. What constitutes an improvement with antibiotic treatment of an exacerbation? Horsley et al ${ }^{14}$ showed that multiple biomarkers improve, but as ever in medicine, the obvious proved to be wrong-sputum markers were not useful. Finally, intravenous anti-Pseudomonal antibiotics also reduce Aspergillus fumigatus in the sputum: ${ }^{15}$ difficult to understand, but emphasising the importance of interactions between species in the CF airways. The final CF manuscript looked longitudinally at quality of life, ${ }^{16}$ increasingly favoured by another favourite whipping boy, the FDA, as a patient reported outcome and showed that health-related quality of life declined slowly, with declining spirometry predicting a decline in quality of life.

We highlighted the sinister ongoing achievements of Mycobacterium tuberculosis with a themed issue to coincide with world TB day in November. Interferonbased tests have been a major diagnostic step forward in recent years, but importantly, in a high prevalence TB area (South Africa) they did not add anything to diagnostic algorithms for active TB in children, ${ }^{17}$ a really important finding in a resource poor area. This manuscript wins the paediatric gold medal for a really practical message, and confirming that the old dogs may not always have to learn new tricks (a relief to your editors). Screening strategies in a resource poor area were formally evaluated, ${ }^{18}$ and for young children, blind treating of contacts was the best approach, also an important resource-saving finding.

Other topics of importance this year include prematurity and its long-term consequences, which continue to be highlighted to bring some much needed new focus to adult chest clinics. ${ }^{19}{ }^{20}$ Basic mechanisms first: important abnormalities in surfactant protein D function were reported in preterm as compared with term infants. ${ }^{21}$ A meta-analysis showed that, although spirometry in some preterm survivors is improving with successive cohorts, even those pretermers with minimal respiratory issues at birth have long-term decrements, so better neonatal intensive care will not solve the problem. $^{22}$ Impaired long-term lung function was confirmed in another cohort study ${ }^{23}$ adult chest physicians take note! Snoring in children has been seen as a source of merriment (Fat Joe in Pickwick Papers, for example); but the increased morbidity in the 3 years before diagnosis, as well as after, and the sevenfold increased mortality in children with obstructive sleep apnoea shown in our silver medal winning paper makes snoring far from a laughing matter. ${ }^{24}$ Finally, obesity again, this time maternal. This seems to predispose to transient infant wheeze, another risk factor for later $\mathrm{COPD},{ }^{25}$ but not allergy. $^{26}$ Thin is beautiful (if not carried to extremes, something of which the editors in chief are not in danger!).

\section{ADULT CLINICAL}

We had several contenders for 2013 Thorax papers of the year in the fields of interstitial lung disease and lung cancer. The pick of these, and the winner of the gold award in this category, is the paper by Shulgina $e t \mathrm{al}^{27}$ describing a large multicentre placebo controlled trial of longterm treatment with cotrimoxazole in patients with idiopathic pulmonary fibrosis. Treatment did not improve the primary outcome but was associated with a fivefold reduction in mortality in participants who were able to take treatment. This finding provided a strong basis for investigating potential microbial factors. Garzoni et $a l^{28}$ did not find any difference in bronchoalveolar lavage bacterial communities in a small pilot study. In contrast, assessment using a similar 16S-based method showed clearly disturbed microbial communities in patients with non-CF bronchiectasis. $^{29}$ There remains debate about the best outcome measures in interstitial lung disease. Thorax did its best to fan the flames of controversy in this area and provided two new outcome measures: 
the King's Sarcoidosis Questionnaire ${ }^{30}$ and the King's Interstitial Lung Disease Questionnaire. $^{31}$ In non-small cell lung cancer, we learnt that aldehyde dehydrogenase1A1 and CD133 expression are associated with worse outcome in patients with early disease. We would like to see papers adding 'unless' to 'worse outcome'. Powell et al ${ }^{32}$ provide a new risk stratification tool for patients undergoing resection of lung cancer. The use of incentive spirometry post-thoracotomy was assessed as a potential 'unless' and found to be wanting by Agostini et $a l^{33}$ in what we felt was an excellent physiotherapy led study, the winner of our bronze award in this category.

Two treatments for obstructive sleep apnoea were evaluated in high quality randomised controlled trials published in Thorax in 2013. The SKUP ${ }^{3}$ trial compared uvulopalatoplasty and expectancy and showed a clinically and statistically significant $60 \%$ reduction in the apnoea index. ${ }^{34}$ In contrast, the nasal expiratory resistance valve Provent was no more effective than placebo. ${ }^{35}$ As with all other chronic medical problems, patients' perception of the importance of treatment can be discordant with the clinicians' leading to poor treatment adherence. Adherence to an oral appliance device was assessed using an ingenious imbedded microsensor thermometer and found to be around $80 \%$ in committed clinical trial participants. ${ }^{36} \mathrm{We}$ bet it would be much less in a more typical population. Perhaps adherence would be better if patients were aware of the increased risk of wake up stroke in those with prolonged apnoeas; ${ }^{37}$ but then again, perhaps not-people do not adhere to treatment for known killers like leukaemia.

The last 20 years have been disappointing for the development of new treatments for airway disease although there have been a few green shoots lately: how far have we really moved from ventolin and becotide for asthma? The green (greenback?) shoots have occurred because researchers have focused more on modifying specific and well-defined aspects of disease and have moved away from arbitrary and unhelpful disease labels. Regrettably we have seen little of this in Thorax in 2013. Findings were either predictable ${ }^{38}$ or unimpressive. ${ }^{39-41}$ One exception, and the winner of the silver medal, was the AZISAST study investigating long-term treatment with low dose azithromycin in patients with moderate to severe asthma. ${ }^{42}$ Treatment was strikingly effective in the subgroup of patients with non-eosinophilic asthma as defined by a blood eosinophil count at baseline of $<0.2 \times 10^{9} / \mathrm{L}$. The blood eosinophil count is the winner of our biomarker of 2013 as compelling evidence suggests that this biomarker might allow clinicians to make better clinical decisions: counts $>0.2 \times 10^{9} / \mathrm{L}$ are associated with a poor outcome in patients with COPD lung attacks who are not treated with prednisolone; ${ }^{39}$ counts $<0.2 \times 10^{9} / \mathrm{L}$ with a better response to placebo than prednisolone; ${ }^{43}$ and counts $<0.05 \times 10^{9} / \mathrm{L}$ a poor outcome generally, probably because they signify significant sepsis. ${ }^{44}$ Peak expiratory flow (PEF) monitoring was an $\mathrm{OK}$ marker of the occurrence of severe asthma lung attacks although there is clearly more to these episodes than airflow limitation as many reported episodes were not associated with a $>20 \%$ fall in PEF. ${ }^{45}$ In subjects with asthma, we learnt that clinical control and inflammation control are not closely linked; ${ }^{46}$ that active eosinophilic airway inflammation may be associated with defective antirhinovirus immunity mediated by increased systemic tryptophan catabolism; ${ }^{47}$ and that climbing to $>6000 \mathrm{~m}$ results in increased symptoms and neutrophil airway inflammation, probably mediated by increased exposure to cold dry air. $^{48}$ (Back to the sofa and PlayStation!)

Pulmonary rehabilitation and peripheral muscle function in patients with COPD was a much more productive area for research and we had several high quality manuscripts in 2013. Much focus is on quadriceps function as this is important, is clearly abnormal in patients with COPD and is treatable. It can be assessed easily and reproducibly using the five-repetition sit-to-stand test ${ }^{49}$ and potentially earlier by detecting muscle-specific messenger RNA in plasma. ${ }^{50}$ Training results in significant improvements in quadriceps strength and size but the molecular mechanisms remain unclear and there is no evidence that the training effect can be augmented by dietary supplements. ${ }^{51}$ Delivering pulmonary rehabilitation in an appropriate and convenient setting remains a challenge. The PRINCE trial showed that a structured primary care-based rehabilitation programme is feasible and may be more accessible for frail elderly patients. ${ }^{52}$

Thorax had a busy year in the pulmonary infection field as both pneumonia and TB were the subjects of themed issues. The use of inhaled steroids was shown to be associated with a marked increased risk of non-tuberculous mycobacterial disease $\mathrm{s}^{53}$ and a modest but dose-related increased risk of TB. ${ }^{54}$ The risk of drug-induced reactivation of $\mathrm{TB}$ is an order of magnitude higher for TNF blockers but currently recommended methods for identifying those at risk may be inadequate as a significant number of patients assessed as being low risk have immunological evidence of latent infection. ${ }^{55}$ Diagnosis of active disease is also not always straightforward and it is often necessary to start treatment before confirmation of the diagnosis. This practice might become a thing of the past as the Xpert MTB/RIF test on bronchoalveolar lavage fluid results in a positive diagnosis more reliably and 30 days more quickly than sputum smear and culture. ${ }^{56}$ Susceptibility to serious lung infection was the topic of several good papers in 2013. Mortality due to pneumococcal pneumonia seems to be more a function of host than bacterial factors. ${ }^{57}$ Host factors that were not considered but which might be relevant include vitamin D deficiency, which was found to be common and associated with more severe disease in patients with bronchiectasis; ${ }^{58}$ and hyperglycaemia, which promotes Staphlococcal aureus infection via a mechanism that is inhibited by metformin. ${ }^{59}$

Finally, the 'you please, you sleaze' award to our sister journal, the $B M J$, for their demonstration of how much the government really cares about public health. Read their expose about how the red carpet was rolled out for the drinks industry to meet everyone in town, evidence was suppressed and anyone who had the temerity to try to put an opposing view (Sarah Wollaston, Tory MP and GP) was ruthlessly blocked. Result-minimum price for alcohol down the drain. Treble trebles all round, and looking good for the tobacco industry, the past masters of these tactics, in 2014.

Funding $A B$ was supported by the NIHR Respiratory Disease Biomedical Research Unit at the Royal Brompton and Harefield NHS Foundation Trust and Imperial College London.

Competing interests None.

Provenance and peer review Not commissioned; internally peer reviewed.

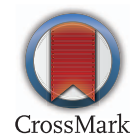

To cite Bush A, Pavord I. Thorax 2014;69:309-311.

Thorax 2014:69:309-311.

doi:10.1136/thoraxjnl-2014-205222

\section{REFERENCES}

1 Clancy JP, Dupont L, Konstan MW, et al. Phase II studies of nebulised Arikace in CF patients with Pseudomonas aeruginosa infection. Thorax 2013:68:818-25.

2 Schuster A, Haliburn C, Döring G, et al. Freedom Study Group. Safety, efficacy and convenience of colistimethate sodium dry powder for inhalation (Colobreathe DPI) in patients with cystic fibrosis: a randomised study. Thorax 2013;68:344-50. 
3 Southern KW, McCormack P, McNamara PS. After a long wait, two arrive, one after the other! Thorax 2013;68:311-12.

4 Serisier DJ, Bilton D, De Soyza A, et al. Inhaled, dual release liposomal ciprofloxacin in non-cystic fibrosis bronchiectasis (ORBIT-2): a randomised, double-blind, placebo-controlled trial. Thorax 2013;68:812-17.

5 Mcllwaine MP, Alarie N, Davidson GF, et al. Long-term multicentre randomised controlled study of high frequency chest wall oscillation versus positive expiratory pressure mask in cystic fibrosis. Thorax 2013;68:746-51.

6 Main E. Airway clearance research in CF: the 'perfect storm' of strong preference and effortful participation in long-term, non-blinded studies. Thorax 2013:68:701-2.

7 Byrnes CA, Vidmar S, Cheney JL, et al. Prospective evaluation of respiratory exacerbations in children with cystic fibrosis from newborn screening to 5 years of age. Thorax 2013:68:643-51.

8 Sanders DB, Hoffman LR, Emerson J, et al. Return of FEV1 after pulmonary exacerbation in children with cystic fibrosis. Pediatr Pulmonol 2010;45:127-34.

9 Sanders DB, Bittner RC, Rosenfeld M, et al. Failure to recover to baseline pulmonary function after cystic fibrosis pulmonary exacerbation. Am J Respir Crit Care Med 2010;182:627-32.

10 Sanders DB, Bittner RC, Rosenfeld M, et al. Pulmonary exacerbations are associated with subsequent FEV 1 decline in both adults and children with cystic fibrosis. Pediatr Pulmonol 2011:46:393-400.

11 de Boer $\mathrm{K}$, Vandemheen $\mathrm{KL}$, Tullis $\mathrm{E}$, et al. Exacerbation frequency and clinical outcomes in adult patients with cystic fibrosis. Thorax 2011;66:680-5.

12 Waters V, Stanojevic S, Atenafu EG, et al. Effect of pulmonary exacerbations on long-term lung function decline in cystic fibrosis. Eur Respir $J$ 2012:40:61-6.

13 Nick JA, Sanders LA, Ickes B, et al. Blood mRNA biomarkers for detection of treatment response in acute pulmonary exacerbations of cystic fibrosis. Thorax 2013;68:929-37.

14 Horsley AR, Davies JC, Gray RD, et al. Changes in physiological, functional and structural markers of cystic fibrosis lung disease with treatment of a pulmonary exacerbation. Thorax 2013;68: 532-9.

15 Baxter CG, Rautemaa R, Jones AM, et al. Intravenous antibiotics reduce the presence of Aspergillus in adult cystic fibrosis sputum. Thorax 2013;68:652-7.

16 Abbott J, Hurley MA, Morton AM, et al. Longitudinal association between lung function and health-related quality of life in cystic fibrosis. Thorax 2013:68:149-54.

17 Ling DI, Nicol MP, Pai M, et al. Incremental value of T-SPOT.TB for diagnosis of active pulmonary tuberculosis in children in a high-burden setting: a multivariable analysis. Thorax 2013;68:860-6.

18 Mandalakas AM, Hesseling AC, Gie RP, et al. Modelling the cost-effectiveness of strategies to prevent tuberculosis in child contacts in a high-burden setting. Thorax 2013;68:247-55.

19 Bolton CE, Bush A, Hurst JR, et al. Are early life factors considered when managing respiratory disease? A British Thoracic Society survey of current practice. Thorax 2012;67:1110.

20 Bolton CE, Bush A. Coming now to a chest clinic near you. Thorax 2013;68:707-8.

21 Kotecha S, Davies PL, Clark HW, et al. Increased prevalence of low oligomeric state surfactant protein $D$ with restricted lectin activity in bronchoalveolar lavage fluid from preterm infants. Thorax 2013;68:460-7.

22 Kotecha SJ, Edwards MO, Watkins WJ, et al. Effect of preterm birth on later FEV1: a systematic review and meta-analysis. Thorax 2013:68:760-6.
23 Vollsæter M, Røksund OD, Eide GE, et al. Lung function after preterm birth: development from mid-childhood to adulthood. Thorax 2013:68:767-76.

24 Jennum P, Ibsen R, Kjellberg J. Morbidity and mortality in children with obstructive sleep apnoea: a controlled national study. Thorax 2013;68:949-54.

25 Edwards CA, Osman LM, Godden DJ, et al. Wheezy bronchitis in childhood: a distinct clinical entity with lifelong significance? Chest J 2003;124:18-24

26 Pike KC, Inskip HM, Robinson SM, et al. The relationship between maternal adiposity and infant weight gain, and childhood wheeze and atopy. Thorax 2013;68:372-9

27 Shulgina L, Cahn AP, Chilvers ER, et al. Treating idiopathic pulmonary fibrosis with the addition of cotrimoxazole: a randomised controlled trial. Thorax 2013;68:155-62.

28 Garzoni C, Brugger SD, Qi W, et al. Microbial communities in the respiratory tract of patients with interstitial lung disease. Thorax 2013;68:1150-6.

29 Rogers GB, van der Gast CJ, Cuthbertson L, et al. Clinical measures of disease in adult non-CF bronchiectasis correlate with airway microbiota composition. Thorax 2013;68:731-7.

30 Patel AS, Siegert RJ, Creamer D, et al. The development and validation of the King's Sarcoidosis Questionnaire for the assessment of health status. Thorax 2013:68:57-65.

31 Patel AS, Siegert RJ, Brignall K, et al. The development and validation of the King's Brief Interstitial Lung Disease (K-BILD) health status questionnaire. Thorax 2012;67:804-10.

32 Powell HA, Tata LJ, Baldwin DR, et al. Early mortality after surgical resection for lung cancer: an analysis of the English National Lung cancer audit. Thorax 2013:68:826-34

33 Agostini P, Naidu B, Cieslik $H$, et al. Effectiveness of incentive spirometry in patients following thoracotomy and lung resection including those at high risk for developing pulmonary complications. Thorax 2013:68:580-5.

34 Browaldh N, Nerfeldt P, Lysdahl M, et al. SKUP3 randomised controlled trial: polysomnographic results after uvulopalatopharyngoplasty in selected patients with obstructive sleep apnoea. Thorax 2013;68:846-53.

35 Rossi VA, Winter B, Rahman NM, et al. The effects of Provent on moderate to severe obstructive sleep apnoea during continuous positive airway pressure therapy withdrawal: a randomised controlled trial. Thorax 2013;68:854-9.

36 Vanderveken OM, Dieltjens M, Wouters K, et al. Objective measurement of compliance during oral appliance therapy for sleep-disordered breathing. Thorax 2013;68:91-6.

37 Ciccone A, Proserpio P, Roccatagliata DV, et al. Wake-up stroke and TIA due to paradoxical embolism during long obstructive sleep apnoeas: a cross-sectional study. Thorax 2013;68:97-104.

38 Busse WW, O'Byrne PM, Bleecker ER, et al. Safety and tolerability of the novel inhaled corticosteroid fluticasone furoate in combination with the beta2 agonist vilanterol administered once daily for 52 weeks in patients $>=12$ years old with asthma: a randomised trial. Thorax 2013:68:513-20.

39 Aaron SD, Vandemheen KL, Maltais F, et al. TNF $\alpha$ antagonists for acute exacerbations of COPD: a randomised double-blind controlled trial. Thorax 2013;68:142-8.

40 Edwards L, Shirtcliffe P, Wadsworth K, et al. Use of nebulised magnesium sulphate as an adjuvant in the treatment of acute exacerbations of COPD in adults: a randomised double-blind placebo-controlled trial. Thorax 2013;68:338-43.

41 MacNee W, Allan RJ, Jones I, et al. Efficacy and safety of the oral p38 inhibitor PH-797804 in chronic obstructive pulmonary disease: a randomised clinical trial. Thorax 2013:68:738-45.
42 Brusselle GG, VanderStichele $C$, Jordens $P$, et al. Azithromycin for prevention of exacerbations in severe asthma (AZISAST): a multicentre randomised double-blind placebo-controlled trial. Thorax 2013:68:322-9.

43 Bafadhel M, McKenna S, Terry S, et al. Blood eosinophils to direct corticosteroid treatment of exacerbations of chronic obstructive pulmonary disease: a randomized placebo-controlled trial. Am J Respir Crit Care Med 2012;186:48-55.

44 Steer J, Gibson J, Bourke SC. The DECAF Score: predicting hospital mortality in exacerbations of chronic obstructive pulmonary disease. Thorax 2012;67:970-6.

45 Kupczyk M, Haque S, Sterk PJ, et al. Detection of exacerbations in asthma based on electronic diary data: results from the 1-year prospective BIOAIR study. Thorax 2013;68:611-18.

46 Volbeda F, Broekema M, Lodewijk ME, et al. Clinical control of asthma associates with measures of airway inflammation. Thorax 2013:68:19-24.

47 van der Sluijs KF, van de Pol MA, Kulik W, et al. Systemic tryptophan and kynurenine catabolite levels relate to severity of rhinovirus-induced asthma exacerbation: a prospective study with a parallel-group design. Thorax 2013;68:1122-30.

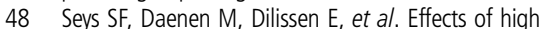
altitude and cold air exposure on airway inflammation in patients with asthma. Thorax 2013;68:906-13.

49 Jones SE, Kon SSC, Canavan JL, et al. The five-repetition sit-to-stand test as a functional outcome measure in COPD. Thorax 2013:68:1015-20.

50 Donaldson A, Natanek SA, Lewis A, et al. Increased skeletal muscle-specific microRNA in the blood of patients with COPD. Thorax 2013;68:1140-9.

51 Constantin D, Menon MK, Houchen-Wolloff L, et al. Skeletal muscle molecular responses to resistance training and dietary supplementation in COPD. Thorax 2013:68:625-33.

52 Casey D, Murphy K, Devane D, et al. The effectiveness of a structured education pulmonary rehabilitation programme for improving the health status of people with moderate and severe chronic obstructive pulmonary disease in primary care: the PRINCE cluster randomised trial. Thorax 2013;68:922-8.

53 Andréjak C, Nielsen R, Thomsen VØ, et al. Chronic respiratory disease, inhaled corticosteroids and risk of non-tuberculous mycobacteriosis. Thorax 2013:68:256-62.

54 Lee C-H, Kim K, Hyun MK, et al. Use of inhaled corticosteroids and the risk of tuberculosis. Thorax 2013;68:1105-13.

55 Singanayagam A, Manalan K, Sridhar S, et al Evaluation of screening methods for identification of patients with chronic rheumatological disease requiring tuberculosis chemoprophylaxis prior to commencement of TNF- $\alpha$ antagonist therapy. Thorax 2013:68:955-61.

56 Theron G, Peter J, Meldau R, et al. Accuracy and impact of Xpert MTB/RIF for the diagnosis of smear-negative or sputum-scarce tuberculosis using bronchoalveolar lavage fluid. Thorax 2013;68:1043-51.

57 Naucler P, Darenberg J, Morfeldt E, et al. Contribution of host, bacterial factors and antibiotic treatment to mortality in adult patients with bacteraemic pneumococcal pneumonia. Thorax 2013:68:571-9.

58 Chalmers JD, McHugh BJ, Docherty C, et al. Vitamin-D deficiency is associated with chronic bacterial colonisation and disease severity in bronchiectasis. Thorax 2013;68:39-47.

59 Garnett JP, Baker EH, Naik S, et al. Metformin reduces airway glucose permeability and hyperglycaemia-induced Staphylococcus aureus load independently of effects on blood glucose. Thorax 2013:68:835-45. 